\title{
الوصول الحر للمعلومات فى الأدبيات العربية
}

\section{د. محهد فتحى عبد الهادى

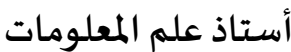

كلية الآداب- جامعة القاهرة

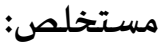

تسعى الدراسة إلى فحص وتحليل النتاج الفكرى العربى المتعلق بالوصول الحر

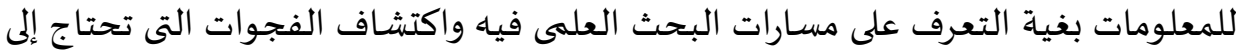
تناول من جانب الباحثين والدارسين. وتعتمد الدراسة على المنهج الببليومترى بفحص وتحليل

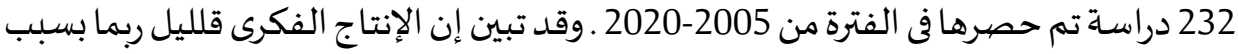

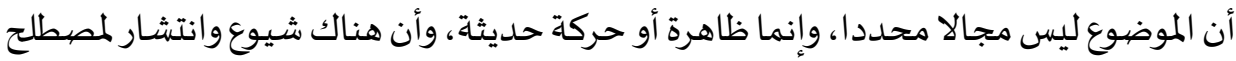

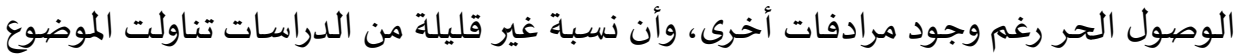

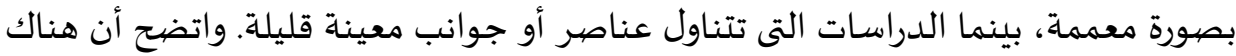
حاجة إلى دراسات جادة عن موضوعات مثل المواد المفتوحة الموجهة لذوى الاحتياجات الخاصة

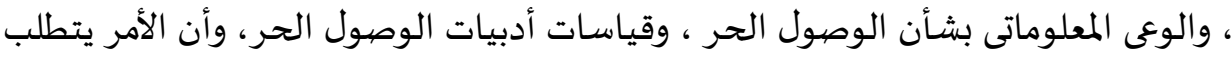
إجراء دراسات عن البيانات المفتوحة باعتبارها عدة المستقبل.

الكلمات المفتاحية: الوصول الحر للمعلومات؛ المستودعات الرقمية؛ الأرشيفات المفتوحة؛؛

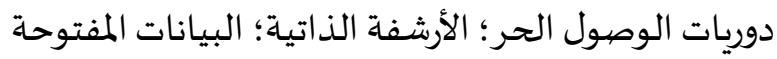


يمثل الوصيول الحر للمعلومات تياراً مهما في عالم المعلومات الرحب من منطق أن الحق فى المعلومات هو حق من حقوق الإنسان وخاصية بعد الارتفاع الملحوظ فى تكلفة الوصيول إلى المعلومات من جانب دور النشر التجارية والمؤسسات أو الشركات التى تنتج قواعد بيانات وتتيحها للاستخدام.

ويننظر للوصيول الحر للمعلومات على أن المعلومات البحثية يمكن الوصهول إليها من خلال

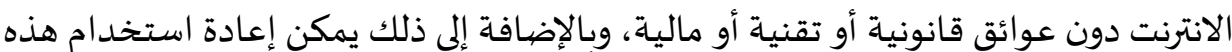
المعلومات بطرق متعددة شريطة أن تحترم حقوق الملكية الفكرية للمؤلفين الأصليين.

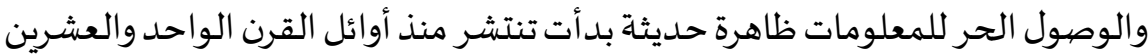
وخاصة بعد شيوع الانترنت وشبكات التواصل الاجتماعى. وقد حظيت هذه الظاهرة أو الحركة بإنتاج أجنبى غزير وصارت مجال اهتمام عديلد من المؤتمرات ، فضلا عن احتفال العالم بأسبوع عالمى للوصول الحر فى أكتوبر من كل عام منذ عام 2010. والسؤال الآن: - nؤن

ما الإسهام العربى من إنتاج فكرى فى هذا المجال؟

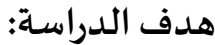

تهدف هذه الدراسة إلى فحص وتحليل النتاج الفكرى العربى المتعلق بالوصول الحر

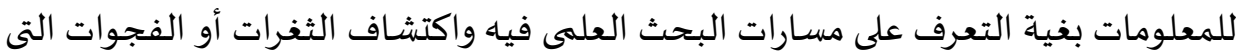
تحتاج إلى تناول من جانب الباحثين والدراسين. تتناول الدراسـة الوصول الحر للمعلومات من حيث مفهومه، ومصيادره، واستخداماته والإفادة منـه، ومبادراته وسياساته، ودور المكتبات في دعم الوصيول الحر وفى نشر ثقافة الوصيول المعلومات وما إلى ذلك. ولا تتطرق الدراسـة إلى النظم مفتوحة المصيدر أو البرمجيات المفتوحة.

وتعتمد الدراسـة على المنهج الببليومترى القائم على استقراء الدراسـات التى كتبت عن الوصيول الحر للمعلومات بعد جمعها من المصيادر. وجدير بالذكر أنهاه تم حصر الدراسـات من

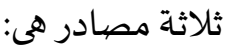
دليل "الإنتاج الفكرى العربى في مجال المكتبات والمعلومات" في الفترة من 2005-2020 عبر المجلدات التالية: 2005-2007، 2008-2009، 2010-2011، 2012-2015، 2016-2020. وقد تم البدء بمجلد 2005-2007 لأنه أول مجلد يخصص رأس موضوع "الوصيول الحر للمعلومات"، فالمجلدات السـابقة على هذا المجلد لم تخصص رأسـا لهذا الموضيوع، وقد أمكن 
حصر (216) دراسة من هذا المصدر.

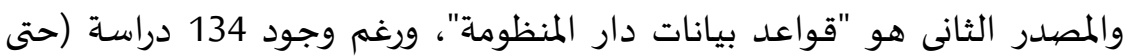

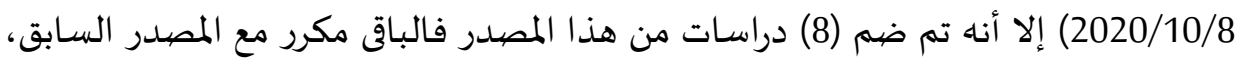

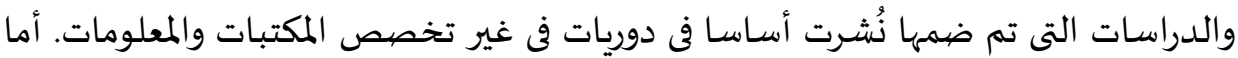

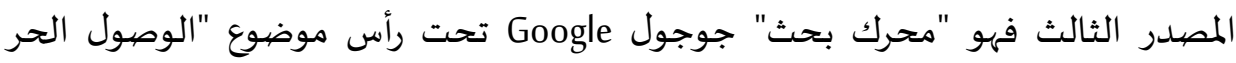

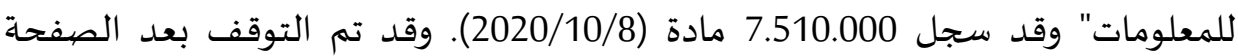
العاشرة، وجرى استبعاد مواد كثيرة غير ملائمة لكناه أمكن إضافة (8) دراسات من هذا هذا المصدر لم تتكرر في المصديدرين السـابقين.

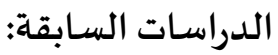
دراسـة وحيدة أمكن التوصل إليها هى دراسـة جميلة جابر (2016) (1)، وهى مراجعة علمية

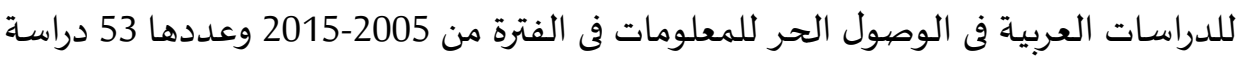

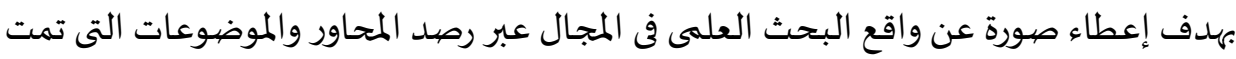

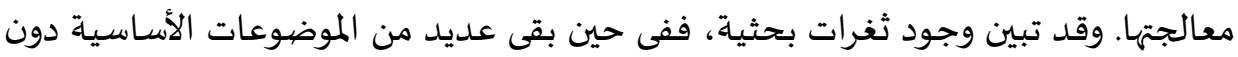

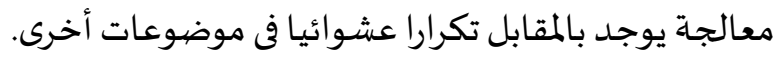

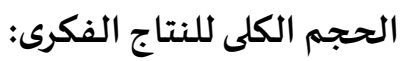

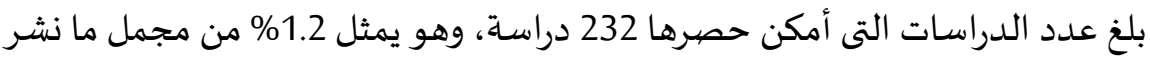

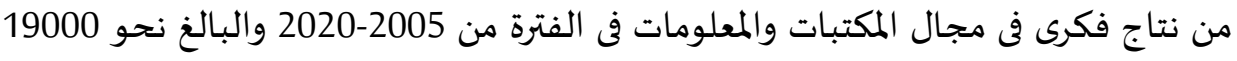

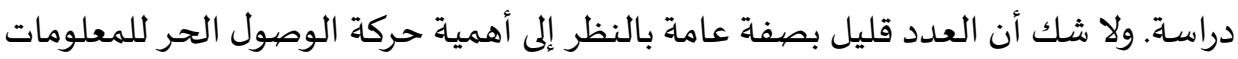
وخاصة بالنسبة للبلاد النامية . التوزيع الزمنى: وخاهية بالنسية يبين جدول (1) توزيع الدراسات عبر السنوات 2005-2020 ، وهو يشير إلى تذبذب واضح

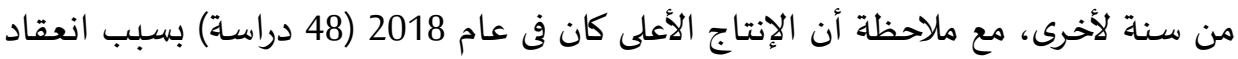

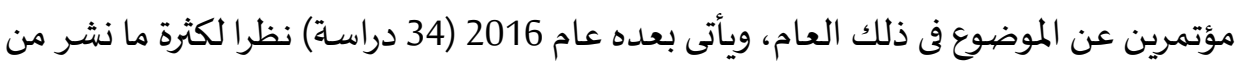

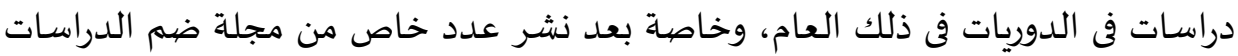

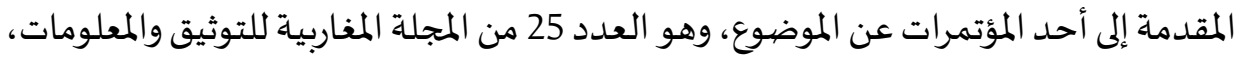

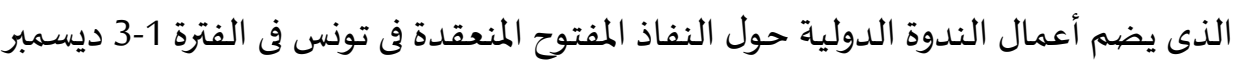
2016

وهذا التوزيع يبين تزايد الإنتاج بشكل واضح فى الفترة الأخيرة (2015-2019)، وهى تمثل 51.7\% من مجمل النتاج. 
جدول (1) التوزيع الزمنى للنتاج الفكرى عبر السنوات 2005-2020

\begin{tabular}{|c|c|c|c|c|c|}
\hline مجموع & كتب & مؤتمرات & رسائل & دوريات & السنة \\
\hline 5 & 0 & 0 & 0 & 5 & 2005 \\
\hline 4 & 1 & 0 & 0 & 3 & 2006 \\
\hline 17 & 0 & 11 & 1 & 5 & 2007 \\
\hline 7 & 0 & 2 & 1 & 4 & 2008 \\
\hline 12 & 0 & 3 & 0 & 9 & 2009 \\
\hline 6 & 0 & 0 & 0 & 6 & 2010 \\
\hline 12 & 0 & 2 & 5 & 5 & 2011 \\
\hline 8 & 1 & 3 & 2 & 2 & 2012 \\
\hline 17 & 1 & 8 & 3 & 5 & 2013 \\
\hline 16 & 0 & 5 & 2 & 9 & 2014 \\
\hline 11 & 1 & 0 & 2 & 8 & 2015 \\
\hline 34 & 2 & 1 & 5 & 26 & 2016 \\
\hline 13 & 1 & 3 & 5 & 4 & 2017 \\
\hline 48 & 0 & 38 & 2 & 8 & 2018 \\
\hline 14 & 1 & 1 & 3 & 9 & 2019 \\
\hline 8 & 0 & 0 & 1 & 7 & 2020 \\
\hline 232 & 8 & 77 & 32 & 115 & الإجمالى \\
\hline
\end{tabular}

ويبين جدول (2) توزيع الإنتاج كل خمس سنوات (ما عدا السنة الأخيرة) . 
جدول (2) التوزيع للانتاج الفكرى كل خمس سنوات

\begin{tabular}{|c|c|}
\hline العدد & الفترة \\
\hline 45 دراسة & 2009-2005 \\
\hline 59 دراسة & 2014-2010 \\
\hline 120 دراسة & 2019-2015 \\
\hline 8 دراسـات & 2020 \\
\hline 232 & الإجمالى \\
\hline
\end{tabular}

توزع الإنتاج الفكرى على 17 دولة منها 15 دولة عربية، و 2 غير عربية (سنغافورة،

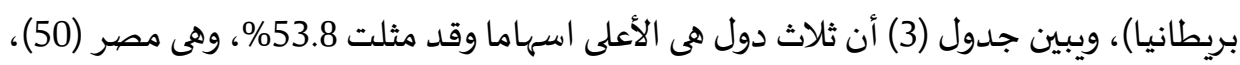

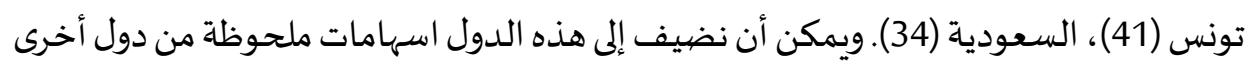

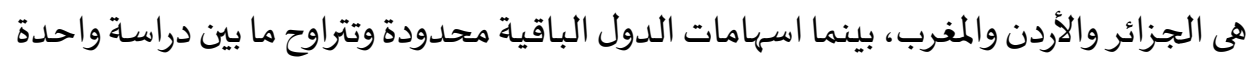
وخمس دراسات.

جدول (3) التوزيع الجغرافى للدراسات

\begin{tabular}{|c|c|c|c|c|c|}
\hline الإجمالى & كتب & رسائل & مؤتمرات & مقالات & الدولة \\
\hline 50 & 3 & 8 & 11 & 28 & مصر \\
\hline 41 & 1 & 0 & 4 & 36 & تونس \\
\hline 34 & 1 & 0 & 14 & 19 & السعودية \\
\hline 29 & 0 & 16 & 1 & 12 & الجزائر \\
\hline 5 & 0 & 0 & 0 & 5 & سوريا \\
\hline
\end{tabular}




\begin{tabular}{|c|c|c|c|c|c|}
\hline الإجمالى & كتب & رسـائل & مؤتمرات & مقالات & الدولة \\
\hline 23 & 1 & 0 & 18 & 4 & الأردن \\
\hline 2 & 0 & 0 & 0 & 2 & ليبيا \\
\hline 2 & 0 & 0 & 0 & 2 & العراق \\
\hline 3 & 0 & 0 & 2 & 1 & البحرين \\
\hline 2 & 0 & 0 & 1 & 1 & الامارات \\
\hline 3 & 0 & 0 & 1 & 2 & غير معلوم \\
\hline 5 & 1 & 0 & 2 & 2 & قطر \\
\hline 22 & 0 & 1 & 20 & 1 & المغرب \\
\hline 2 & 0 & 1 & 1 & 0 & السـودان \\
\hline 1 & 0 & 0 & 1 & 0 & سنغافورة \\
\hline 4 & 0 & 3 & 1 & 0 & عمان \\
\hline 3 & 1 & 2 & 0 & 0 & لبنان \\
\hline 1 & 0 & 1 & 0 & 0 & بربطانيا \\
\hline 232 & 8 & 32 & 77 & 115 & المجموع \\
\hline
\end{tabular}

التوزيع حسب أنواع الدراسـات:

تتوزع الدراسـات على أربعة أشكال من المصادر هى: مقالات الدوريات، الدراسات المقدمة

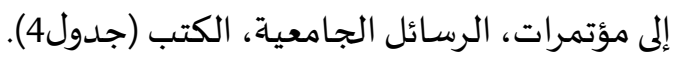


جدول (4) التوزيع النوعى للدراسـات

\begin{tabular}{|c|c|c|}
\hline النسبة المئوية & العدد & النوع \\
\hline$\% 49.6$ & 115 & مقالات الدوريات \\
\hline$\% 33.2$ & 77 & دراسـات المؤتمرات \\
\hline$\% 13.8$ & 32 & رسائل جامعية \\
\hline$\% 3.4$ & 8 & كتب \\
\hline$\% 100$ & 232 & المجموع \\
\hline
\end{tabular}

ومن الواضح أن مقالات الدوريات قد حظيت بالنصيب الأكبر (حوالى نصف الدراسات) يليها دراسات المؤتمرات.

وفيما يتعلق بالدوريات نجد أن الدراسات المنشورة بها موزعة على (38 دورية منها 11 دورية غير تخصصية ، وأبرز هذه الدوريات : بالدويهات نجدئ
26
المجلة المغاربية للتوثيق والمعلومات (تونس)
14
Cybrarians Journal
6
اعلم (تونس)
5
بحوث في علم المكتبات والمعلومات (مصر)
5
ببليوفيليا (الجزائر)

وقد قدمت هذه الدوريات الخمس (56 دراسـة) بنسبة 48.7\% من مجمل دراسات

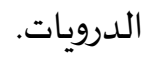

ويلاحظ أن إنتاج الدوريات مشتت لدرجة كبيرة كما يظهره جدول (5) . 
جدول (5) انتاج الدوريات

\begin{tabular}{|c|c|}
\hline عدد الدراسات & 18 \\
\hline 1 & 8 \\
\hline 2 & 3 \\
\hline 3 & 4 \\
\hline 4 & 2 \\
\hline 5 & 1 \\
\hline 6 & 1 \\
\hline 14 & 1 \\
\hline 26 & \\
\hline
\end{tabular}

وفيما يتعلق بدراسـات المؤتمرات (77) نجد أنها مقدمة لـ 24 مؤتمرا منها مؤتمران عن

الموضوع (35 دراسـة) بنسبة 46\% بأحدهما في الرباط (2018):

Third International Colloquium on Open Access

والثانى في عمان (2018) :

المؤتمر الدولى للمكتبات والمعلومات والتوثيق : الوصول الحر للمعلومات

ويلاحظ أن لمؤتمرات الاتحاد العربى للمكتبات والمعلومات السنوية اسهام جيد (12)

وتجدر الإشـارة إلى أن هناك بعض أعمال المؤتمرات الأخرى التى نشرت في أعداد خاصية

من الدوريات ومن ثم اعتبرت دراسات دوريات.

أما الرسائل الجامعية وعددها (32) رسالة فنصفها (16) جاء من الجزائر وتسعة منها من

جامعة قسنطينة 2 جدول (6) . 
جدول (6) الرسائل الجامعية عن الوصهول الحر للمعلومات

\begin{tabular}{|c|c|c|c|c|}
\hline المجموع & دكتوراه & ماجستير & دبلوم & البلد \\
\hline 16 & 1 & 15 & - & الجزائر \\
\hline 8 & 3 & 5 & - & مصر \\
\hline 3 & - & 3 & - & سلطنة عمان \\
\hline 2 & 1 & 1 & - & لبنان \\
\hline 1 & - & 1 & - & السودان \\
\hline 1 & - & - & 1 & المغرب \\
\hline 1 & 1 & - & - & بربطانيا \\
\hline 32 & 6 & 25 & 1 & المجموع \\
\hline
\end{tabular}

ولجامعات مصر مساهمة لا بأس بها في هذا المجال، فقد قدمت ثلاث رسائل للدكتوراه

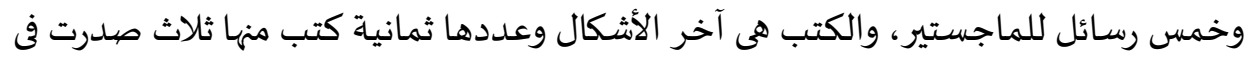

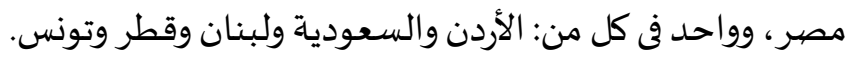

وجدير بالذكر أن هناك كتابين مترجمين إلى اللغة العربية أحدهما صهدر فى قطر هو

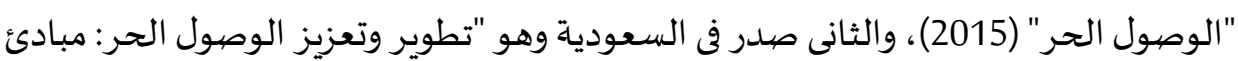
توجيهية للسياسات" (2017).

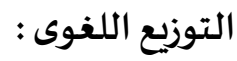

من الطبيعى أن تكون اللغة العربية هى التى حظيت بالنصيب الأكبر من الدراسـات 80.2\% يليها اللغة الفرنسية 16.8\% بسبب اسهامات كل من تونس والمغرب، ثم اللغة الإنجليزية 3\%

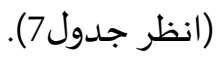


جدول (7) التوزيع اللغوى

\begin{tabular}{|c|c|c|c|c|c|}
\hline المجموع & كتب & رسـائل جامعية & مؤتمرات & مقالات & اللغة \\
\hline 186 & 8 & 29 & 57 & 92 & العربية \\
\hline 39 & - & 1 & 17 & 21 & الفرنسية \\
\hline 7 & - & 2 & 3 & 2 & الإنجليزية \\
\hline 232 & 8 & 32 & 77 & 115 & المجموع \\
\hline
\end{tabular}

يبن جدول (8) أكثر المؤلفين اسهامات بالكتابة عن الوصول الحر للمعلومات (خمس

دراسات فأكثر)

$$
\text { جدول (8) المؤلفون }
$$

\begin{tabular}{|c|c|c|c|c|}
\hline المجموع & كتب & مؤتمرات & مقالات & المؤلف \\
\hline 13 & 1 & 1 & 11 & عبد الرحمن فراج \\
\hline 7 & 1 & 2 & 4 & وحيد قدورة \\
\hline 5 & - & - & 5 & آمنة بهلول \\
\hline 5 & 1 & 1 & 3 & إيمان رمضيان محمد \\
\hline 5 & - & 4 & 1 & طارق الورفلى \\
\hline 35 & 3 & 8 & 24 & المجموع \\
\hline
\end{tabular}

ويبين الجدول أن د. عبد الرحمن فراج (أستاذ المكتبات والمعلومات بجامعة بنى سويف

ومؤسس المجموعة العربية للوصول الحر) على رأس القائمة بمساهمات بلغت 13 دراسـة. 


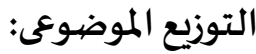

$$
\text { يبين جدول (9) التوزيع الموضوعى للدراسات عن الوصول الحر . }
$$

جدول (9) التوزيع الموضيوعى لدراسات الوصول الحر

\begin{tabular}{|c|c|c|}
\hline النسبة & العدد ال العد & الموضوع \\
\hline$\% 33.6$ & 78 & الوصيول الحر (عام) \\
\hline$\% 29.8$ & 69 & مصادر الوصول الحر \\
\hline$\% 15.1$ & 35 & الاستخدام والتوجهات \\
\hline$\% 11.6$ & 27 & المكتبات والوصول الحر \\
\hline$\% 4.3$ & 10 & المبادرات والسياسـات \\
\hline$\% 3$ & 7 & البيانات المفتوحة \\
\hline$\% 2.6$ & 6 & قضايا ومسائل معينة \\
\hline$\% 100$ & 232 & المجموع \\
\hline
\end{tabular}

ويتضح للوهلة الأولى كثرة عدد الدراسـات التى تتناول الموضيوع بصفة عامة فهى تمثل نحو

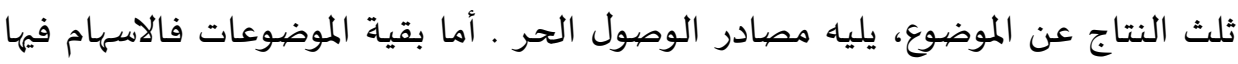

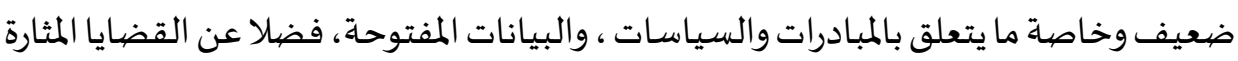
في هذا المجال مثل الوصول الحر والملكية الفكرية ، وأخلاقيات الوصيول الحر وما إلى ذلك.

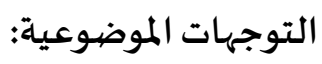

$$
\text { عن مفهوم الوصول الحر للمعلومات : }
$$

إن مفهوم الوصول الحر للمعلومات يتسم بالوضوح بصفة عامة فهو يقوم على عدة

أولا: الارتباط أساسا بالمعلومات الرقمية المتاحة من خلال الانترنت والويب. 
ثانيا: أن المقصود بالمعلومات هو المعلومات المفيدة في أغراض الدراسـة والبحث ومن ثم تستبعد بصفة عامة معلومات المدونات والأخبار المتاحة في جوجل مثلا، والملصقات وما شابه.

ثالثا: أن الاتاحة والوصول أو النفاذ يتمان دون عوائق قانونية أو تقنية أو مالية، ويعنى ذلك

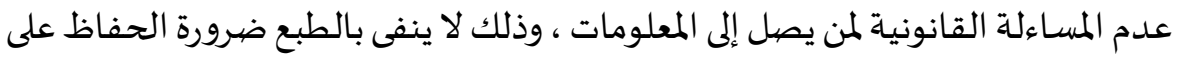

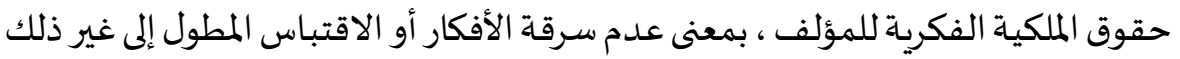

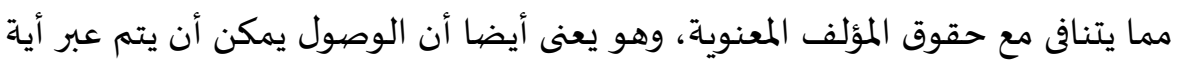

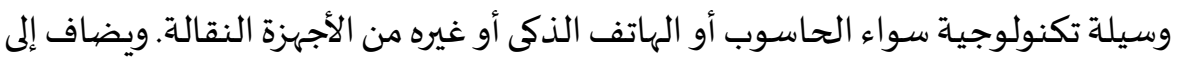
ذلك أن الاتاحة هى مجانية ولا تتطلب دفع رسوم من قبل المستخدم: ونشيل ونشير أيضا إلى أنها

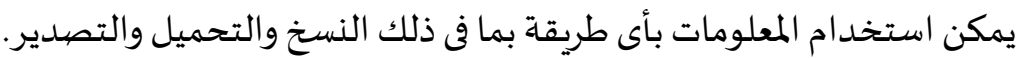
ومع أن الأمر واضح على النحو السالف ذكره إلا أن هناك اختلافات فى وجهات النظر

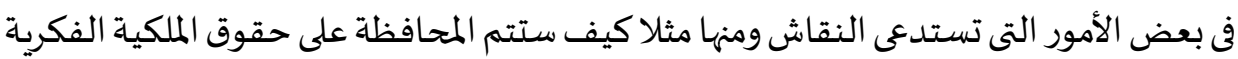
فى ظل إتاحة حرة لأناس غير معلومين وعلى أوسع نطاق ممكن، وكيف سيتم الضبط في ظل تنوع وسائل تحميل المعلومات ونقلها عبر وسائل التواصل الاجتماعى المتعددة و غيرها، وماذا بشأن الاستنساخ لأغراض تجارية وإمكانية معرفتها ومحاسبة المسؤولين عنها. اختلافات حول المصطلح العربى:

إذا كان المصطلح الشائع بالإنجليزية هو Open Access وبالفرنسية Libre Access فما

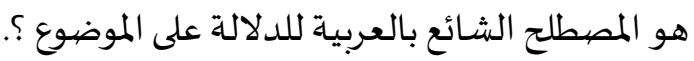
تبين دراسة مها رمضان (2011)(2) ودراسة يونس الشوابكة (2019) (3) تعدد المقابلات

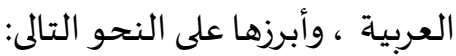

$$
\text { الوصيول الحر الوصول الوصول المفتوح }
$$




\section{النفاذ المفتوح}

\section{الاتاحة المجانية}

$$
\text { الاتاحة الحرة }
$$

ويؤكد الشوابكة على أن مصطلح الوصول الحر هو الأكثر شيوعا وتداولا بين الباحثين

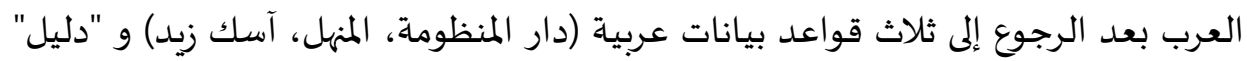
الإنتاج الفكرى العربى فى مجال المكتبات والمعلومات. ومن ناحية أخرى يحبذ سهيل هوسة (2016) (4) مصطلح "النفاذ المفتوح" بعد دراسـة

الوصول للحر للمعلومات زهرة عالم الانفتاح المعلوماتى: للانفتاحية مظاهرها المتعددة في عصر المعلومات(5)، وللمصيادر المفتوحة عالمها الواسع(6)

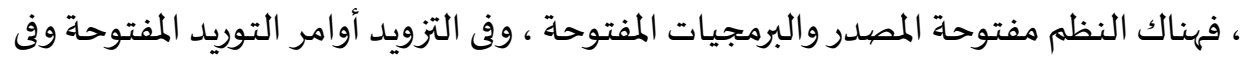

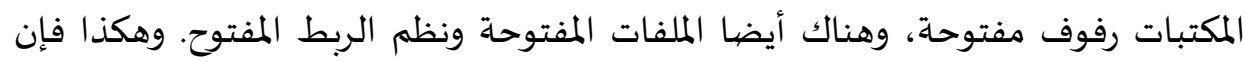
الوصول الحر هو جزء من هذا العالم الانفتاحى، بل هو زهرتها الناضرة.

$$
\text { الوصول الحرللمعلومات حركة حديثة: }
$$

رغم أن مفهوم الوصول الحر قديم بصفة عامة، فالعلم كان حرا في عصيور النهضة

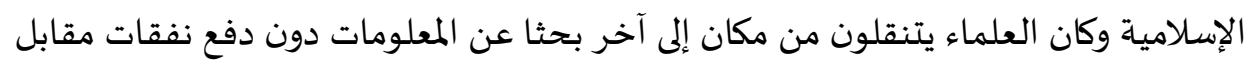

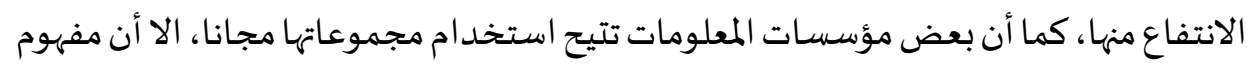
الوصول الحر ارتبط في الوقت الحاضر بالمعلومات الرقمية أساسا ، ولذلك فإن الكان الكتابات

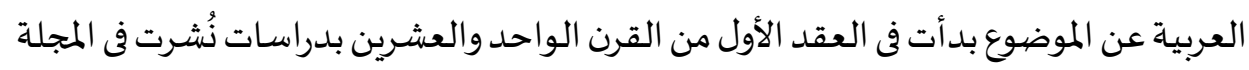

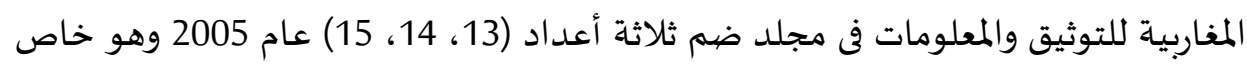

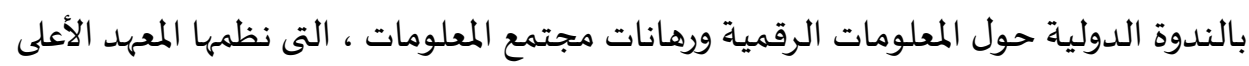


للتوثيق بتونس 14-16 أبريل 2005، وأول مقالة باللغة العربية في الحصر الحالى عن الأرشيفات

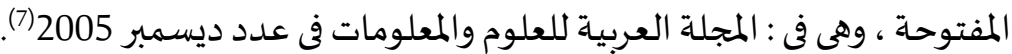
وقد شهد عام 2006 صدور اول كتاب عن الموضوع ل وحيد قدورة ، كما شهد عام 2007 أول أطروحة ماجستير أجيزت في قسم علم المكتبات والتوثيق بجامعة الجزائر ل كريمة بن علال. عمومية تناول الوصول الحر للمعلومات هى الغالبة: يغلب طابع العمومية في الكتابة عن الموضوع (78 دراسة بنسبة 33.6\%) ، فالدراسات قد

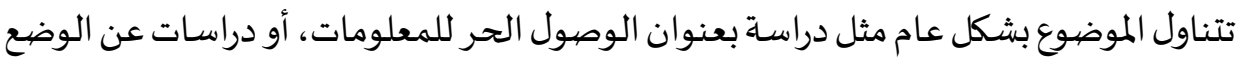

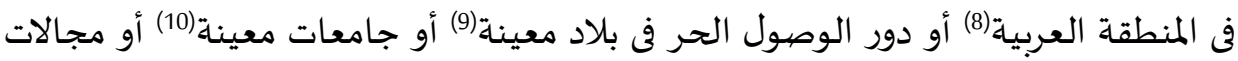

معينـة (11)

(13)، ومن الدراسات العامة ما يتناول مدى تأثير الوصول الحر على البحث العلىى(12) أو النشر العلمى(14) ، ومنها ما يركز على مشروعات معينة للوصول الحر (15)، فقد تناولت أزهار جاسم (2019) (16) أهم المشروعات العراقية في تحقيق الوصول الحر للمعلومات مات مثركات مثل منصية

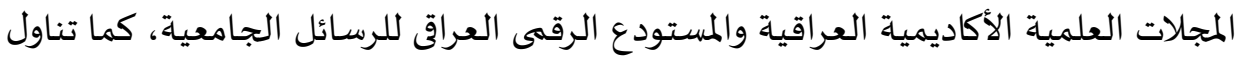

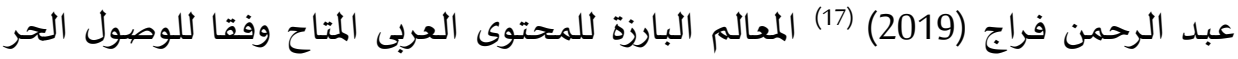
ومشروعاته وسياساته والتحديات التى تواجه البلاد العربية في هذا السياق. ومن الأعمال العامة اللافتة للنظر كتاب وحيد قدورة الصادر عام 2006(18) عن الاتصال العلىى والوصول الحر إلى المعلومات العلمية الذى يتناول- فى وقت مبكر بالنسبة للموضيوع -

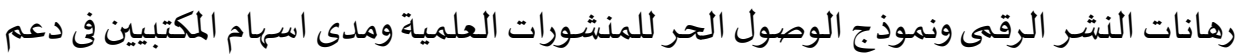
النموذج وتحليل درجة اندماج الباحثين والناشرين والمكتبيين العرب في الحوار القائم حول الوصول الحر فى البيئة البحثية والمعلوماتية. أيضا كتاب فوز عبد الله (2016) (19) الذى يشير إلى أن حق وحرية المواطن فى الوصهول إلى المعلومات هو السبيل إلى الشفافية والمسـاءلة. 


\section{مصادر الوصول الحر متعددة ولكن ! :}

الباحثون عن المعلومات يصلون إليها من خلال مصيادر متعددة متاحة على الانترنت،

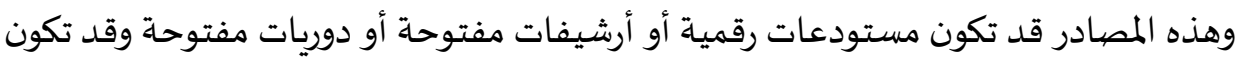

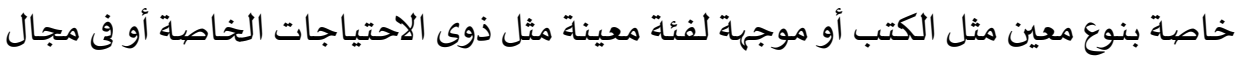

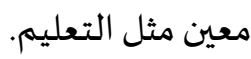

وقد تناولت (69) دراسة عربية بنسبة 29.8\% المصيادر المتعددة للوصول الحر.

وتعتبر المستودعات الرقمية والأرشيفات المفتوحة هى أهم هذه الفئات، حيث توجد 18 دراسـة عن المستودعات الرقمية و19 دراسة عن الأرشيفات المفتوحة.

وتصف بعض الدراسات وتحلل مستودعات مؤسسات قائمة وخاصية في الجامعات

كذلك في موضوعات معينة مثل الطب أو لأشكال معينة مثل الرسائل.

وأهم دراسة في هذا السياق هى رسالة الدكتوراة لإيمان فوزى (2011) (20) عن

المستودعات الرقمية المفتوحة كمصددر من مصادر الاقتناء بالمكتبات الجامعية.

وتتناول بعض الدراسات واقع الأرشيفات المفتوحة في الوطن العربى (طارق الورفلى ومحمد بن رمضان) (21)، أو آليات بناء مستودع أرشيف مفتوح ومعايير التقييم (أمنة بهلول

(22) $(2016$

وقد حظيت دوريات الوصول الحر وأدلتها بـ 14 دراسة منها دراسـة نهال إسماعيل (2011)(23) عن دوريات الوصيول الحر وتأثيرها على الدوريات المطبوعة في مجال المكتبات والمعلومات، وعرض غدير مجدى عبد الوهاب للدليل الذى أعدتاه وهو دليل الدوريات العربية المجانية (24).

وفى المقابل نجد أن الدراسات عن المصادر المفتوحة الأخرى مثل الكتب أو المكتبات

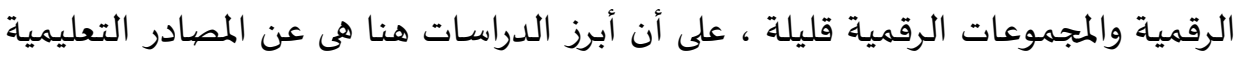

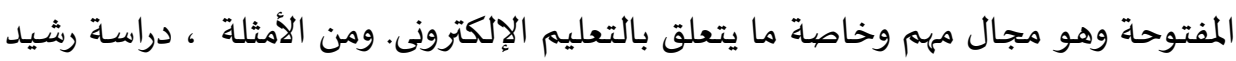

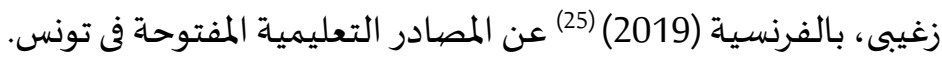


وترتبط الأرشفة الذاتية بمصادر الوصول الحر، فهى قد تكون في مستودعات مؤسسية

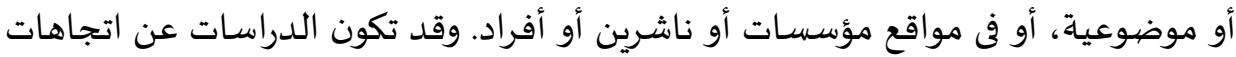

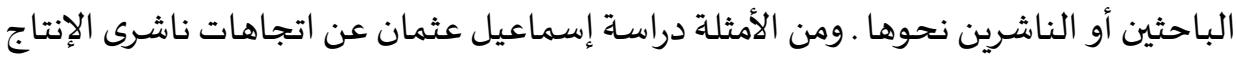

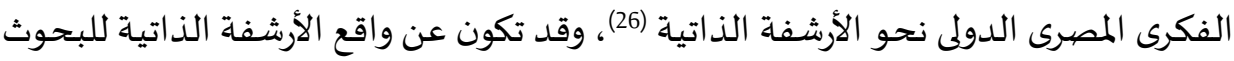
في الجامعات (27). (27)

\section{الاستخدام والإفادة من الوصيول الحر:}

الدراسات كثيرة نسبيا في هذا القطاع (35 دراسة بنسبة 15.1\%) وهى مبكرة أيضا، منها دراسة وحيد قدورة (2006) عن مواقف الباحثين التونسيين من استخدام الأرشيف المفتوح والدوريات المتاحة مجانا على الخط (28).

ومن دراسـات الاستخدام رسالة الماجستير (2012) لـ دينا عادل عن أنماط الإفادة من

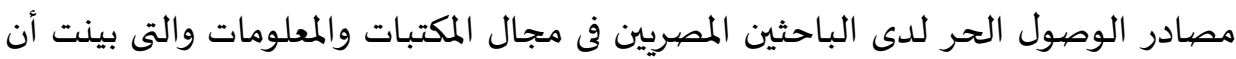

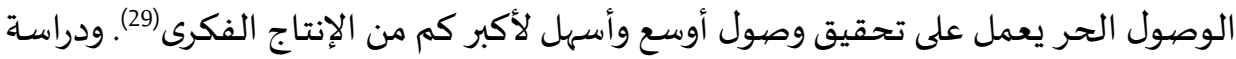
حنان بيزان (2020) عن واقع حركة الوصول الحر للمعلومات: دراسة لاتجاهات الأكاديميين الليبيين لنشر إنتاجهم الفكرى عبر الانترنت (30). عموما ، الدراسات في هذا القطاع تهتم باتجاهات المستفيدين تجاه الوصول الحر للمعلومات ومدى الاستفادة منه ودعماه والإسهام فياه. للمكتبات دور مهم ومؤثرفى الوصهول الحرللمعلومات : تتناول بعض الدراسات (27 دراسة بنسبة 11.6\%) جوانب مختلفة مثل دور المكتبات في دعم الوصول الحر، والدور فى نشر ثقافة الوصول، والعوائق، ودور الاختصاصى. ومن الدراسات في هذا السياق: دراسة رحاب سويفى (2016) عن دور اختصاصى المكتبات والمعلومات في

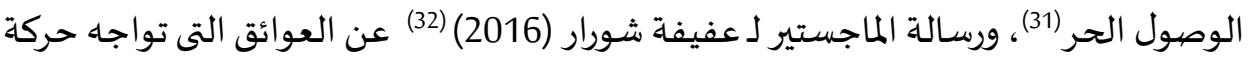
الوصول الحر بالمكتبات الجامعية بالجزائر. 


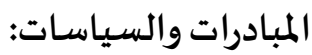

تعتبر مبادرات التدفق الحر للمعلومات ذات أهمية في نشر الوعى وفى دعم الوصول الحر

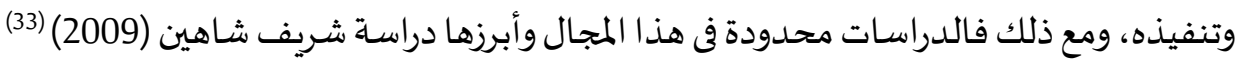

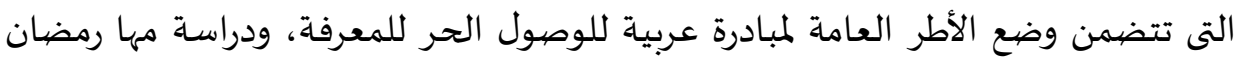
(2011) (34) ، وهى أطروحة دكتوراه عن مبادرات التدفق الحر للمعلومات العلمية واستنباط أسس مبادرة مصرية. ورغم أهمية سياسات الوصول الحر إلا أهها لم تحظ باهتمام هى الأخرى (4 دراسات) منها كتاب مترجم إلى العربية عن تطوير وتعزيز الوصول الحر: مبادئ توجيهية للسياسات (2017)

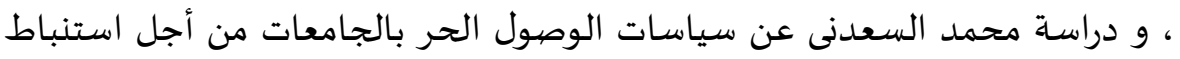

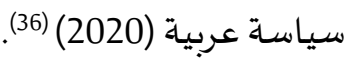
البيانات المفتوحة هى المستقبل: يهتم العالم الآن بالبيانات ومدى مساهمتها في النهوض بالمبات بالعلم والتنمياة وما إلى ذلك ونشأ من أجلها علم جديد هو علم البيانات. ومن ضمن مظاهر الاهتمام ما يتعلق بالبيانات المفتوحة.

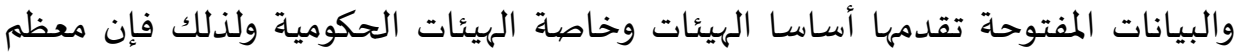

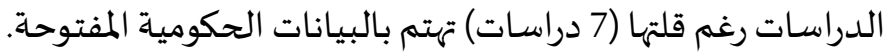

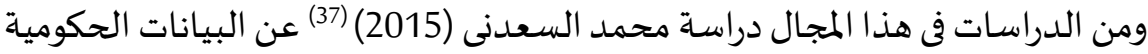

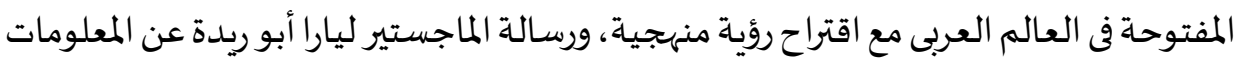

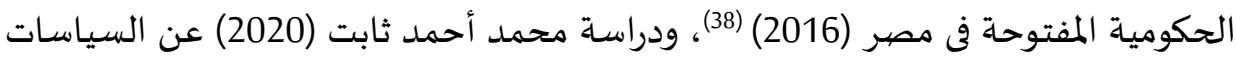

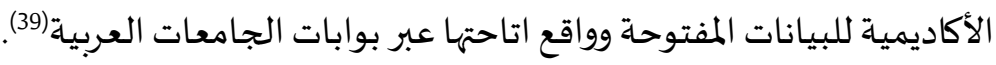
الوصول الحروحقوق الملكية الفكرية :

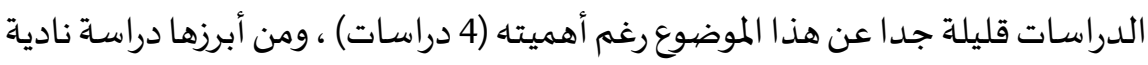
عولمى (2018) التى تتناول تبنى تراخيص العموميات الخلاقة بالمكتبات بين حقوق الملكية

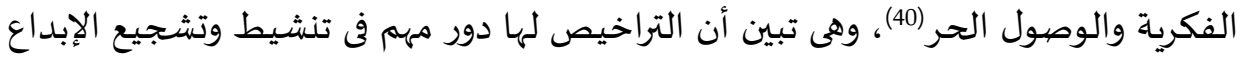
الفكرى على الانترنت. استنتاجات:

أسفرت الدراسة للأدبيات العربية الخاصة بالوصول الحر للمعلومات عن النتائج التالية: - - الإنتاج الفكرى قليل (232 مادة) ربما بسبب أن الموضوع ليس مجالا محددا وإنما 


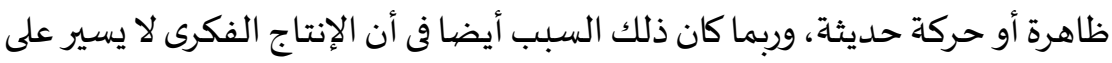

وتيرة واحدة وإن شهد ارتفاعا واضحا في السنوات الخمس الأخيرة (2015-2019). - - على الرغم من أن أكثر من نصف النتاج الفكرى من ثلاثة دول هى مصر وتونس

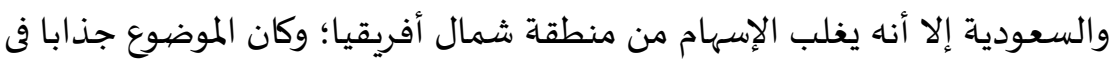
عقد مؤتمرات وإعداد أطروحات جامعية.

- - هناك اختلافات بالنسبة للمصطلح العربى الدال على الموضوع مع شيوع وانتشار

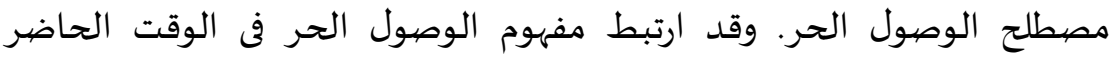

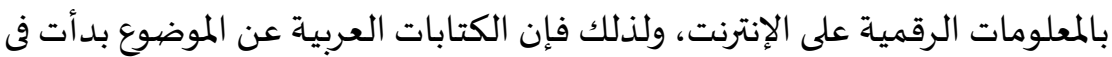

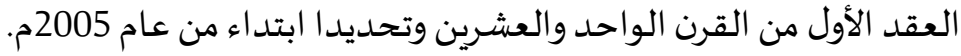
- - نسبة كبيرة من الدراسات تتناول الموضيوع بصورة معممة بينما الدراسات التى تتناول عناصر أو جوانب محددة مثل السياسـات أو المبادرات قليلة.

خاتمة:

يتطلب الأمر اهتمام الباحثين بمزيد من الدراسـات العلمية الجادة عن الوصول الحر

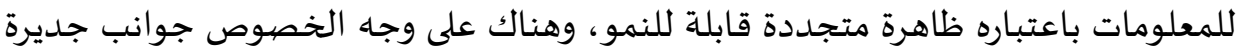

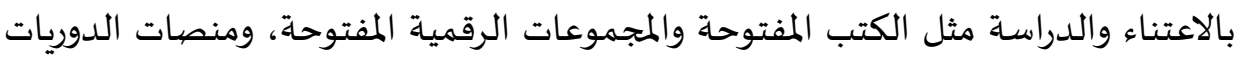

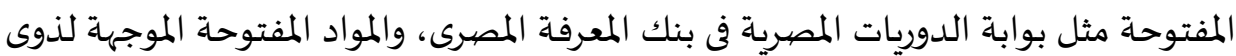

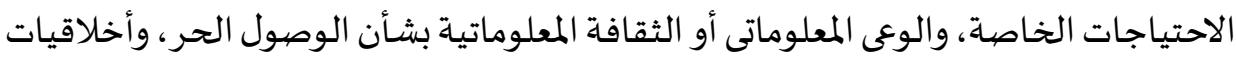

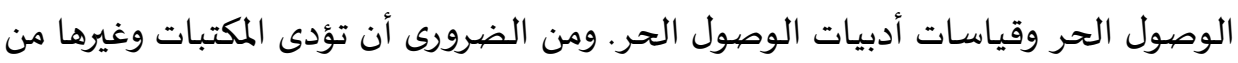

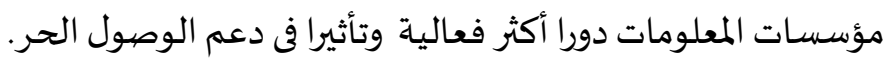

ونأمل أن نجد إجابات فى المستقبل القريب عن تساؤلات حول حجم النتاج الفكرى

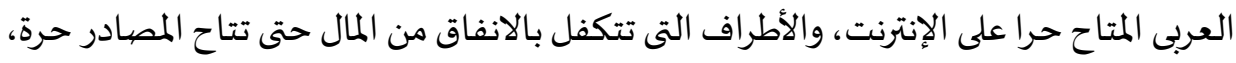

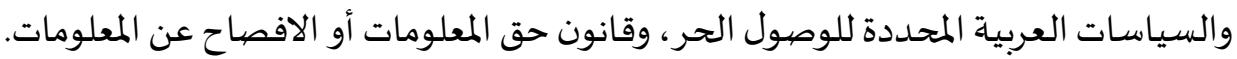
ويبقى أننا نشهد حاليا ثورة فى البيانات بصفة عامة والبيانات المفتوحة بصفة خاصةة، وهو ما يستدعى الاهتمام بإعداد دراسات علمية متعددة حول البيانات المفتوحة. 


\section{المصيادر}

جابر، جميلة. مراجعة الدراسات العربية في الوصول الحر للمعلومات، 2005-2015.-

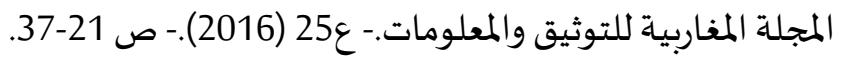

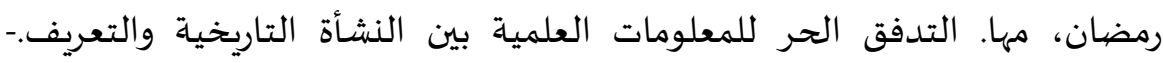
(3).Cybrarians Journal

الشوابكة، يونس. ظاهرة تعدد المقابل العربى للمصطلحات الأجنبية في علم المكتبات

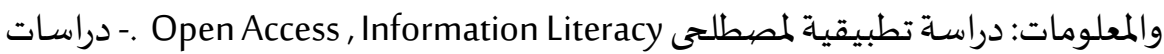

$$
\text { : العلوم التربوية.- مج46، وراسه تطبيقيه (2019).-- ص 49-65. }
$$

هويسة، سهيل. النفاذ المفتوح: في المفهوم والمصطلح.- المجلة المغاربية للتوثيق

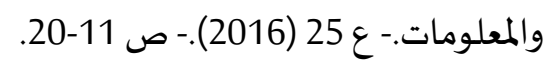

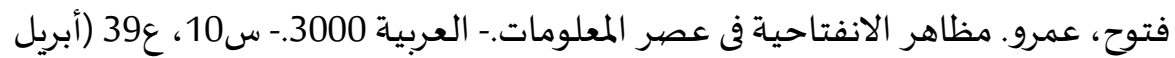

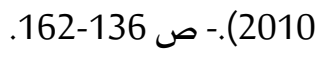

عالم المصادر المفتوحة وبرمجيتها: دراسات تأصيلية/ إعداد حسناء محمود محجوب...

$$
\text { [وأخ].- الإسكندرية: دار الثقافة العلمياة، 2012.- }
$$

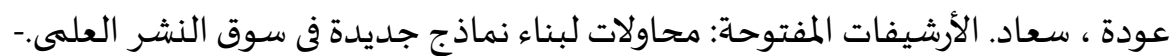

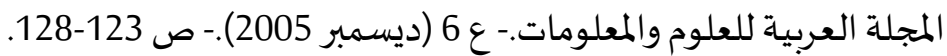

(8) جابر ، جميلة . الوصول الحر في البلدان العربية والهيمنة المعرفية الغربية: دراسـة

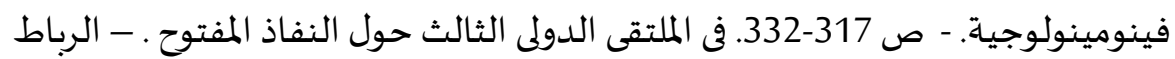

.2018،

حمدى، هدى. النفاذ المفتوح فى تونس: الواقع والتحديات.- ص 135-151. فى المؤتمر

$$
\text { الدولى حول الوصول الحر للمعلومات.- عمان، }
$$

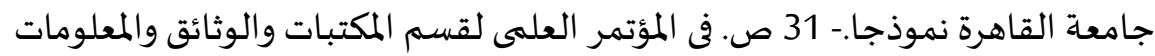
بكلية الآداب جامعة القاهرة.- القاهرة، 2013.

عبد الهادى، محمد فتحى. النفاذ إلى المعلومات العلمية والتقنية على الإنترنت: دراسـة المادها

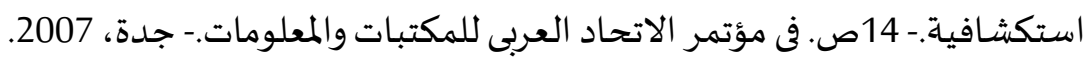


فايز، رحاب. فرص الاستفادة من سرعة النفاذ الحر للمعلومات فى ترقية البحث العلىى

$$
\text { بالدول العبية/ رحاب فايز، عمر حوتية.-- ببليوفيليا.- ع3 (2019).- ص 5 50-90. }
$$

1) فروخى، الويزة. دور الوصول الحر فى دعم التكوين والبحث العلمى.- الجزائر، 2011.

$$
\text { أطروحة (ماجستير) - جامعة الجزائر . }
$$

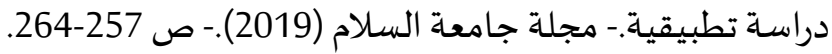

درويش، مريم. مشروعات الوصول الحر لاتاحة الكتب على الانترنت: دراسة تحليلية

تقييمية.- القاهرة، 2016. أطروحة (ماجستير)- جامعة القاهرة.

(16) جاسم، أزهار. المبادرات العراقية وتحقيق الوصول الحر للمعلومات: التجربة العراقية

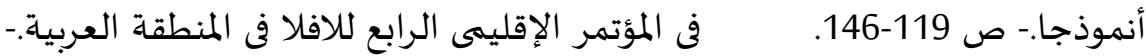

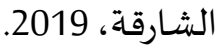

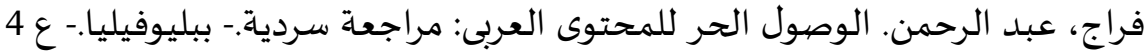

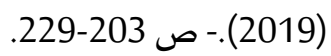

قدورة، وحيد. الاتصال العلمى والوصول الحر إلى المعلومات العلمية.- تونس: المنظمة العربية للتربية والثقافة والعلوم، 2006.- 311ص.

عبد الله، فوز. الوصول الحر إلى المعلومات: مواطنة، شفافية، مساءلة.- بيروت: دار

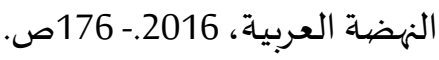

(20) عمر، إيمان فوزى. المستودعات الرقمية المفتوحة كمصدر من مصادر الاقتناء بالمكتبات الجامعية: دراسة تحليلية.- القاهرة، 2011. أطروحة (دكتوراه)- جامعة حلوان. (21) الورفلى، طارق. النفاذ الحر وإتاحة الإنتاج العلمى: واقع الأرشيفات المفتوحة في الوطن

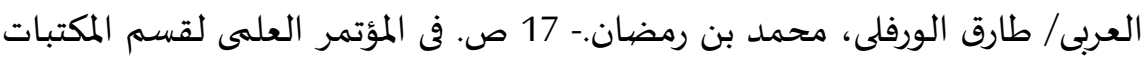

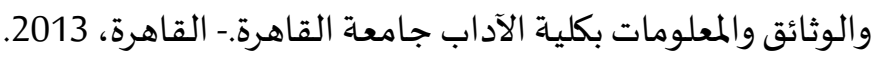
بهلول ، آمناة . آليات بناء مستودع الأرشيف المفتوح المؤسساتى : قواعد الانشاءو و معايير

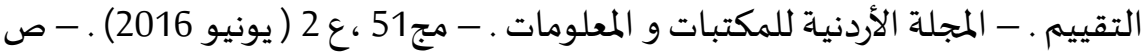

$$
.93-65
$$

2) 
المطبوعة في مجال المكتبات والمعلومات.- بحوث فى علم المكتبات والمعلومات.- ع6 (مارس

$$
\text { 2011). ص ص 2011 }
$$

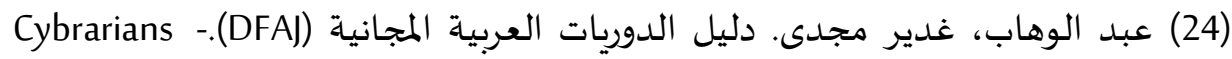

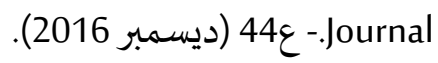

$$
\text { زغيبى، رشيد . }
$$

Resources pedagogiques numeriques gratuites et en access libe en Tunisie.Revue Maghribne de Documentation et d'Information.- No.28 (2019).- p. 23-48.

(26) عثمان ، إسماعيل رجب . اتجاهات ناشرى الإنتاج الفكرى المصرى الدولى نحو الأرشفة

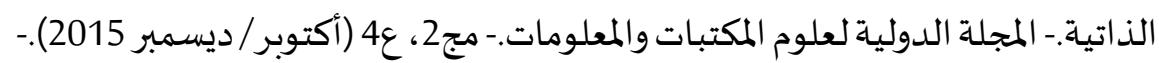
ص ص 270-237. ابن غيدة ، وسام يوسف ـ الأرشفة الذاتية للبحوث العلمية بالجامعة الجزائرية : دراسة

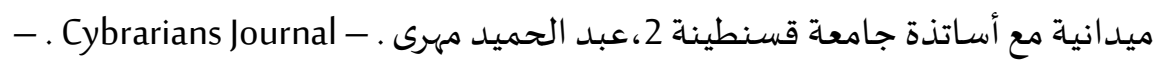

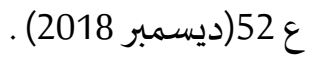

قدورة، وحيد. استخدام الأرشيف المفتوح والدوريات المتاحة مجانا على الخط: مواقف عالف

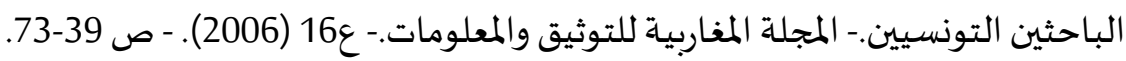

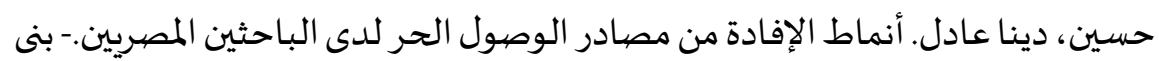

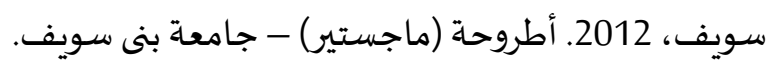

(30) بيزان ، حنان الصادق. واقع حركة الوصول الحر للمعلومات: دراسة لاتجاهات الأكاديميين الليبيين لنشر إنتاجهم الفكرى عبر الإنترنت.-

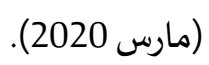

سويفى، رحاب. دور أخصائى المكتبات والمعلومات في الوصول الحر للمعلومات: دراسة

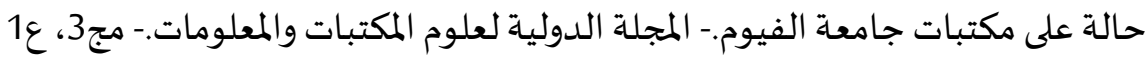

$$
\text { (يناير / مارس 2016).-- ص 199-227. }
$$

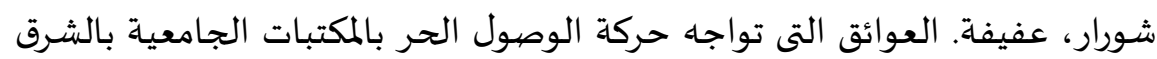

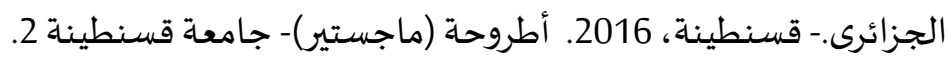


(33) شاهين، شريف. مبادرات الوصول الحر للمعرفة: دراسة وثائقية لوضع الأطر العامة

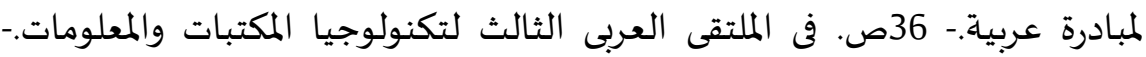

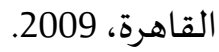

رمضان ، مها محمد. مبادرات التدفق الحر للمعلومات العلمية: دراسة تحليلية لاستنباط

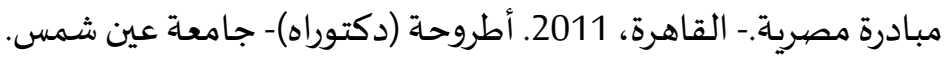

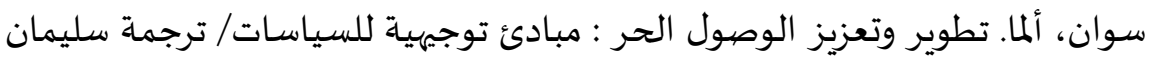
الشهرى، عبد الرحمن فراج.- الرياض: مدينة الملك عبد العزيز للعلوم والتقنية، 2017. 184

(36) السعدنى، محمد عبد الرحمن · سياسات الوصول الحر بالجامعات: دراسة مسحية

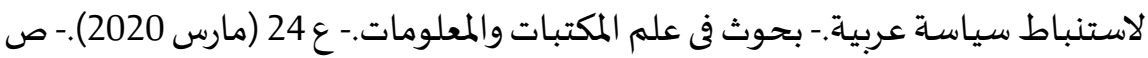
$.330-299$

السعدنى، محمد عبد الرحمن. البيانات الحكومية المفتوحة في العالم العربى: دراسة

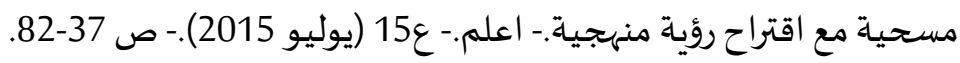

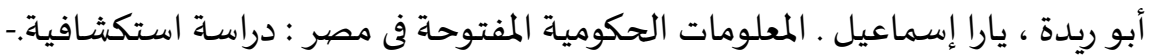
القاهرة، 2016. أطروحة (ماجستير)- جامعة القاهرة.

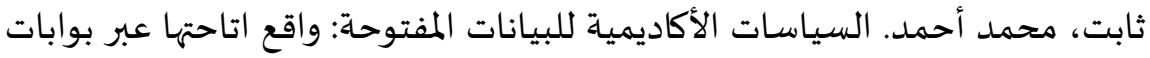

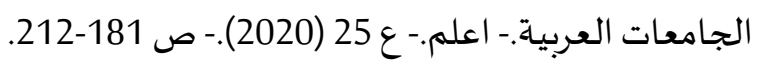

(40) عولمى، نادية. تبنى العموميات الخلاقة بالمكتبات ومرافق المعلومات بين حقوق الماتهات الملكية

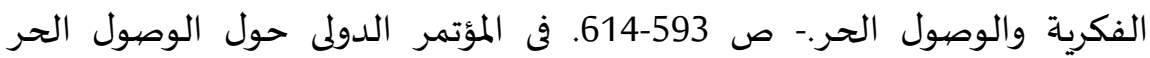
للمعلومات.- عمان، 2018. 